\title{
Inline Ka-band Transitional Combline / Evanescent-Mode Filter in Conventional RF Substrate Using Grounded Vias
}

\author{
Tinus Stander \\ Carl and Emily Fuchs Institute for Microelectronics \\ Dept. EEC Engineering, University of Pretoria \\ Pretoria, South Africa \\ tinus.stander@ieee.org
}

\begin{abstract}
The Ka-band is considered a viable band for future 5G backhaul links. Planar filters in this frequency range have low aspect ratios for substrates thicker than $10 \mathrm{mil}$, since the required $50 \Omega$ line width becomes comparable to a guided wavelength. This paper proposes the use of grounded throughhole plated vias as transitional combline / evanescent-mode resonators. The principle is demonstrated with a $4^{\text {th }}$ order, $27.5-$ $29.5 \mathrm{GHz}$ filter in a conventional 32 mil thickness RF substrate. The simulated filter features below $2 \mathrm{~dB}$ insertion loss across the band and occupies $3.8 \times 1 \mathrm{~mm}$ board space.
\end{abstract}

Index Terms - Microwave filters, microstrip filters, substrates.

\section{INTRODUCTION}

Millimeter wave frequencies have received recent interest as band of choice for future 5G communication networks [1], with the Ka-band channels at $28 \mathrm{GHz}$ and $38 \mathrm{GHz}$ exhibiting favorable propagation characteristics in urban environments. Although filters at these frequencies have been successfully demonstrated in conventional metal waveguide [2], on-chip [3], LTCC [4] and LCP [5] media, conventional PCB processes on RF soft substrates are cheaper for low production volumes.

Millimeter wave planar transmission line resonators are typically realized on 10 mil [6] or 5 mil [7] substrates because the guided wavelength becomes comparable to the width required by a $50 \Omega$ transmission line on thicker substrates. This leads to low aspect ratio resonators. The use of substrate integrated waveguide [8] is a viable solution to this shortcoming, but these occupy significantly more board space than a coplanar waveguide (CPW) or microstrip transmission line filter of equivalent frequency and order.

Grounded via holes in conventional soft substrates [9][10] have been shown suitable for realizing resonators in conventional soft substrates, occupying less space than horizontal etched lines [11] or capacitively loaded SIW resonators [12] that delimit cavities with via holes. The most important shortcoming to the state-of-the-art on this filter topology is, however, that neither the use of either coupled TEM line [13] nor coupled resonator [12] synthesis techniques have been demonstrated in realizing these filters.

This paper contributes to the state-of-the-art of coupled grounded via resonator filters by presenting a coupled resonator synthesis, demonstrating implementation in a conventional two-layer substrate, and first time implementation at $\mathrm{K}_{\mathrm{a}}$-band frequencies. In all cases, full-wave EM simulation is performed with CST Microwave Studio 2014 using the general purpose frequency domain solver with tetrahedral mesh.

\section{FILTER GEOMETRY}

The proposed filter geometry is shown in Fig. 1. The filter is implemented on a single substrate of height $h$ and fed by a grounded coplanar waveguide line of width $w_{f}$ and gap width $g_{f}$. Each resonator consists of a rectangular patch of width $w_{n}$ and length $l_{n}$ grounded in the center by a through-hole plated via of diameter $d_{v n}$, with resonators $n$ and $n+l$ separated by a gap $d_{n, n+l}$. The upper grounded shields are connected to the lower ground by vias of diameter $d_{s}$ and pitch $d_{p}$ such that the two opposing via rows form a channel too narrow to support a $\mathrm{TE}_{10}$ substrate integrated waveguide (SIW) mode

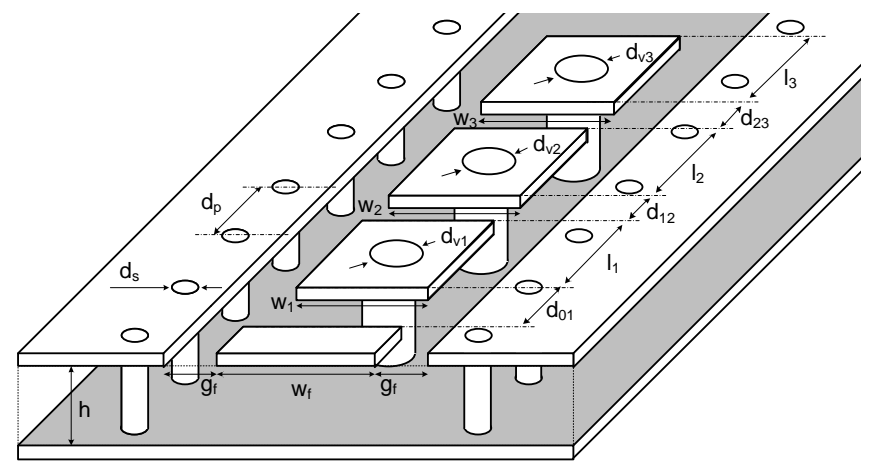

Fig. 1. Basic filter geometry.

The categorization of this filter as transitional combline / evanescent-mode filter is in keeping with the nomenclature established in [14]. The resonant E-field plot in Fig. 2 indicates a coaxial resonance as opposed to a cavity resonance observed in evanescent-mode SIW resonators [12] or evanescent half-mode resonators [15]. 


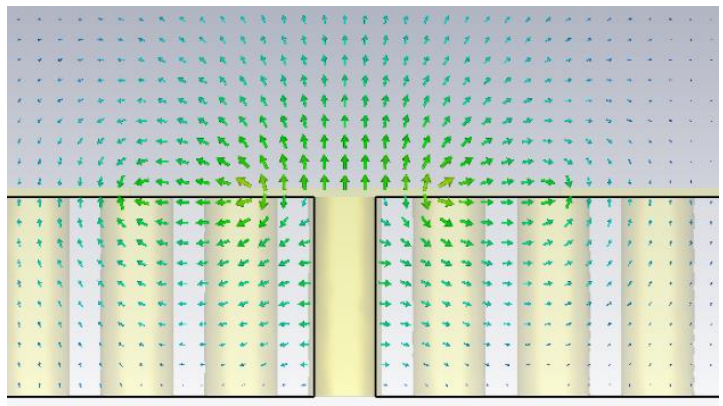

Fig. 2. $y z$-plane cross section of $E$-field at resonance.

The resonant frequency is therefore not only controlled by the size of the capacitive load (as set by the size $d_{n}=w_{n}=l_{n}$ ) but also the height of the substrate (Fig. 3). This supports the coupled resonator (as opposed to coupled TEM line, as is used for true combline filters) design approach, with full-wave EM $\mathrm{CAD}$ tools used to evaluate the mixed electric/magnetic coupling between adjacent resonators.

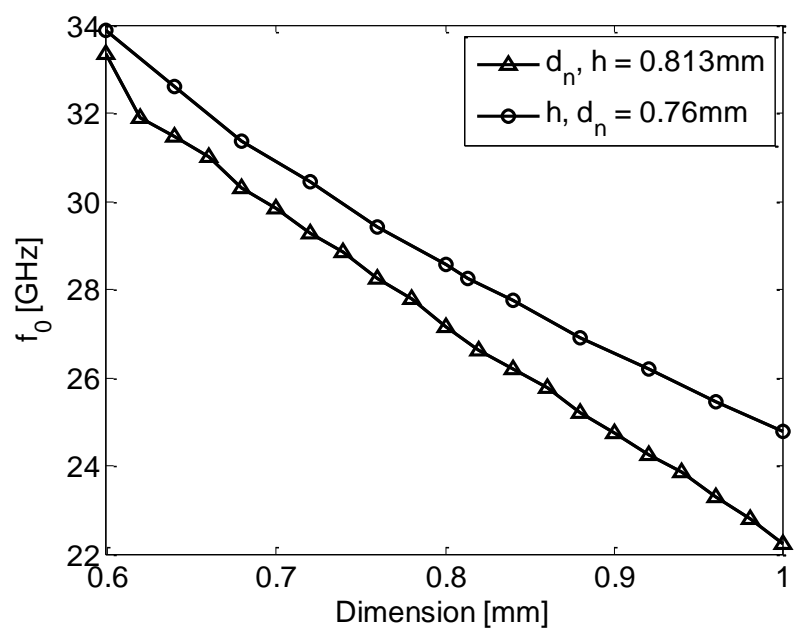

Fig. 3. Variation in resonant frequency by altering $d_{n}$ (for constant $h$ ) or $h$ (for constant $d_{n}$ ).

\section{SYNTHESIS AND SIMULATION}

To demonstrate the design, a $4^{\text {th }}$ order Chebyshev filter is synthesized to cover the FCC and ITU regulated $27.5-29.5$ $\mathrm{GHz}$ fixed microwave communications band. Following the conventional CAD-assisted synthesis of microwave coupled resonator filters [16], the theoretical synthesis requires resonator coupling values $k_{12}=k_{34}=0.0563, k_{23}=0.0451$ and external Q-factor $Q_{e}$ of 17.04. The filter is simulated on Rogers RO4003C of thickness $32 \mathrm{mil}(0.813 \mathrm{~mm})$.
As is expected with electric coupling, $Q_{e}$ is proportional to $d_{01}$ (Fig. 4) while $k_{n, n+1}$ is inversely proportional to $d_{n, n+1}$ as shown in Fig. 5.

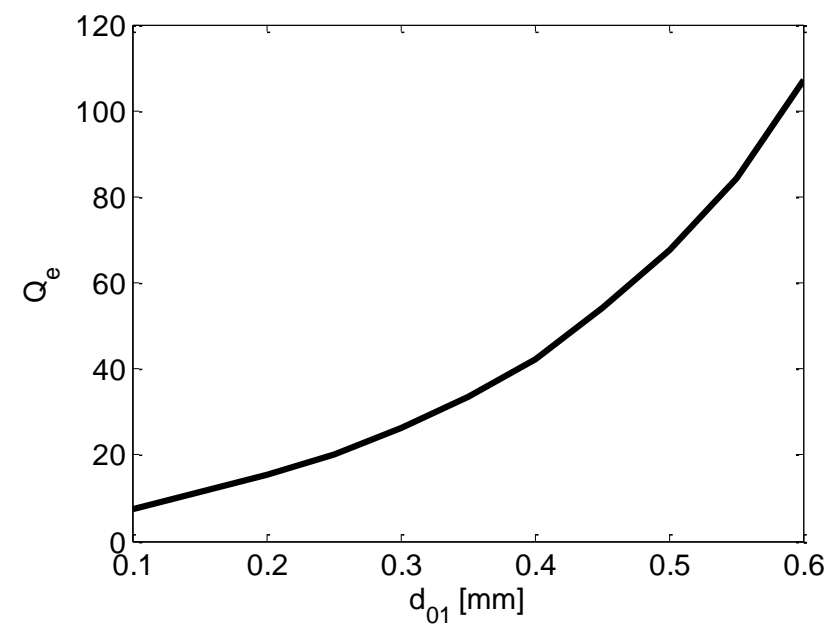

Fig. 4. $Q_{e}$ vs. $d_{01}$

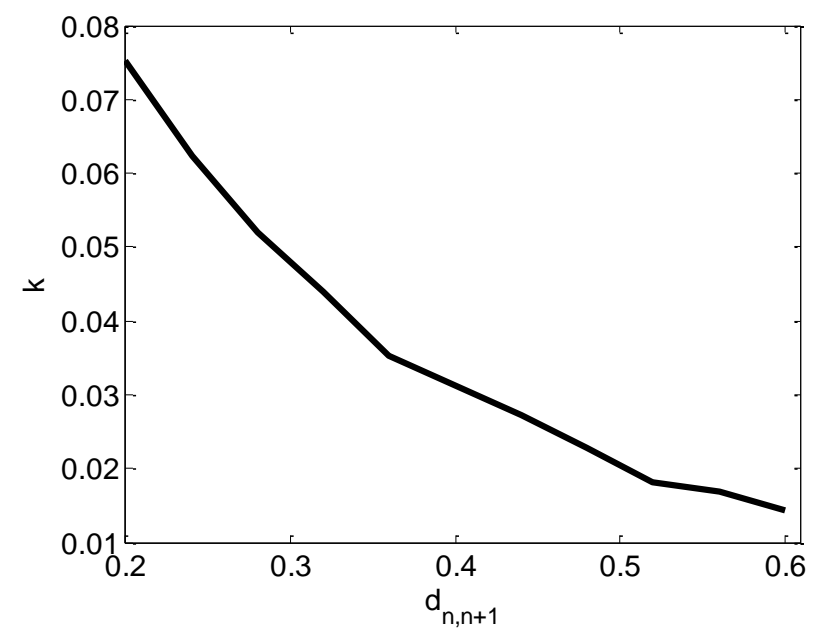

Fig. 5. $\quad k$ vs. $d_{n, n+1}$

The final filter is dimensioned as shown in Table 1, with simulated results shown in Fig. 6. The filter exhibits below 2 $\mathrm{dB}$ insertion loss across the band of interest, and occupies 3.8 x $1 \mathrm{~mm}$ board space. Compared to other single layer soft substrate filters (Table II) is evident that, not only is this the first time a Ka-band filter has been presented in a substrate thicker than $0.5 \mathrm{~mm}$, but that it represents the state-of-the-art in footprint size for filters around $28 \mathrm{GHz}$. 
TABLE 1: FINAL FILTER DIMENSIONS

\begin{tabular}{|l|c|}
\hline \multicolumn{1}{|c|}{ Dimension } & Value $[\mathbf{m m}]$ \\
\hline $\mathrm{h}$ & 0.813 \\
\hline $\mathrm{d}_{01} ; \mathrm{d}_{45}$ & 0.11 \\
\hline $\mathrm{d}_{12} ; \mathrm{d}_{34}$ & 0.17 \\
\hline $\mathrm{d}_{23}$ & 0.21 \\
\hline $\mathrm{w}_{1,4} ; \mathrm{l}_{1,4}$ & 0.75 \\
\hline $\mathrm{w}_{2,3} ; \mathrm{l}_{2,3}$ & 0.77 \\
\hline $\mathrm{d}_{\mathrm{v} 1-4}$ & 0.25 \\
\hline $\mathrm{d}_{\mathrm{s}}$ & 0.3 \\
\hline $\mathrm{d}_{\mathrm{p}}$ & 0.45 \\
\hline $\mathrm{w}_{\mathrm{f}}$ & 0.95 \\
\hline $\mathrm{g}_{\mathrm{f}}$ & 0.15 \\
\hline
\end{tabular}

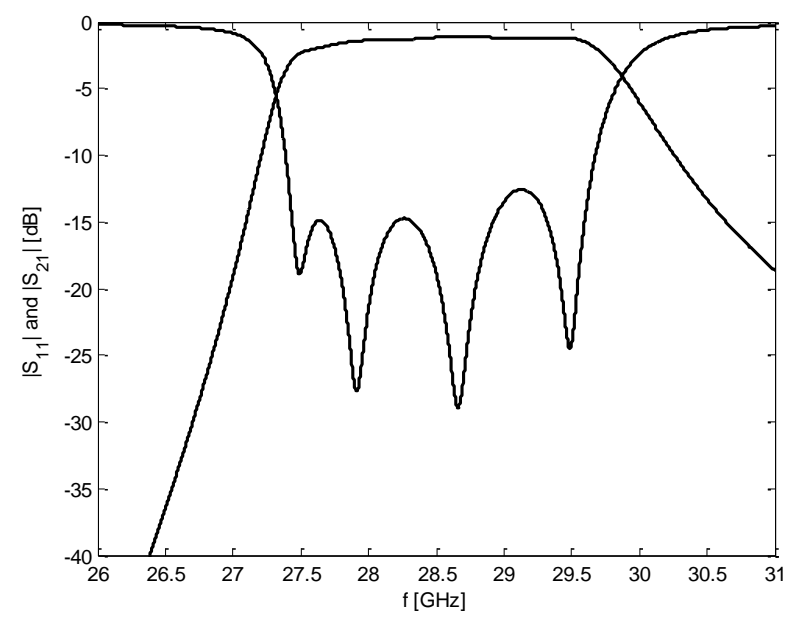

Fig. 6. Simulated S-parameters of filter

TABLE 2: COMPARISON TO OTHER SINGLE LAYER KA-BAND SOFT SUBSTRATE FILTERS

\begin{tabular}{|l|l|l|l|l|l|l|l|}
\hline & $\begin{array}{l}\mathrm{f}_{0} \\
(\mathrm{GHz})\end{array}$ & FBW & $\begin{array}{l}\text { Filter } \\
\text { order }\end{array}$ & $\begin{array}{l}\text { IL } \\
(\mathrm{dB})\end{array}$ & $\begin{array}{l}\text { Substrate } \\
\varepsilon_{\mathrm{r}}\end{array}$ & $\begin{array}{l}\text { Height } \\
(\mathrm{mm})\end{array}$ & $\begin{array}{l}\text { Size } \\
\left(\mathrm{mm}^{2}\right)\end{array}$ \\
\hline $\begin{array}{l}\text { This } \\
\text { Work }\end{array}$ & 28.5 & $7 \%$ & 4 & 2 & 3.55 & 0.813 & 3.8 \\
\hline$[6]$ & 35 & $7.1 \%$ & 3 & 2.5 & 2.2 & 0.25 & 585 \\
\hline$[17]$ & 35.8 & $33 \%$ & 6 & 0.74 & 2.2 & 0.25 & 174.4 \\
\hline$[18]$ & 28.9 & $4.5 \%$ & 3 & 0.8 & 2.2 & 0.25 & 8.5 \\
\hline$[19]$ & 31.5 & $41 \%$ & 5 & 0.5 & 2.2 & 0.25 & 4.0 \\
\hline$[20]$ & 38.5 & $2 \%$ & 2 & 1.85 & 2.2 & 0.25 & 229 \\
\hline$[21]$ & 36 & $5 \%$ & 2 & 3 & 2.2 & 0.25 & 3.6 \\
\hline$[22]$ & 28 & $2.2 \%$ & 2 & 4.7 & 2.2 & 0.13 & 7.6 \\
\hline$[23]$ & 28 & $3.5 \%$ & 3 & 1.1 & 2.2 & 0.51 & 80.8 \\
\hline$[24]$ & 35 & $3.7 \%$ & 4 & 1.25 & 2.94 & 0.51 & 75.7 \\
\hline
\end{tabular}

\section{CONCLUSION}

Grounded vias in conventional RF substrate have been shown an effective resonant structure for transitional combline / evanescent-mode filters. The class of filter represents the state-of-the-art in compactness and easy to construct in conventional RF PCB processes. Future work will include introducing cross-coupled structures and extending the work to E-band frequencies on conventional 10 mil substrates.

\section{ACKNOWLEDGEMENT}

This work was supported by the National Research Foundation (NRF) of South Africa under Grants UID92526 and UID93921, as well as the UNESCO Participation Programme.

\section{REFERENCES}

T. S. Rappaport, Shu Sun, R. Mayzus, Hang Zhao, Y. Azar, K. Wang, G. N. Wong, J. K. Schulz, M. Samimi, and F. Gutierrez, "Millimeter Wave Mobile Communications for 5G Cellular: It Will Work!," Access, IEEE, vol. 1, pp. 335349, May 2013.

[2] M. Zhao and Y. Fan, "A Ka band low loss wideband Eplane waveguide filter," in 2011 IEEE 4th International Symposium on Microwave, Antenna, Propagation, and EMC Technologies for Wireless Communications (MAPE), 2011, vol. 1, pp. 802-804.

[3] J. Zhu, Y. Yu, N. Yang, B. Zhou, and Y. Zhang, "Micromachined silicon via-holes and interdigital bandpass filters," Microsyst. Technol., vol. 12, no. 10-11, pp. 913917, Sep. 2006.

[4] B. G. Choi, M. G. Stubbs, and C. S. Park, "A Ka-band narrow bandpass filter using LTCC technology," IEEE Microw. Wirel. Components Lett., vol. 13, no. 9, pp. 388389, Sep. 2003.

[5] Xia Zhang, D. Kuylenstierna, J. Liu, Peng Cai, C. Andersson, J. Morris, and H. Zirath, "A compact V-band planar wideband bandpass filter based on Liquid Crystal Polymer substrates," in 2nd Electronics System-Integration Technology Conference, 2008., 2008, pp. 163-168.

[6] W. Zhao, Y. Zhang, and Y. Guo, "A novel Ka-band bandpass filter using microstrip closed loop resonators," in 2009 Asia Pacific Microwave Conference, 2009, pp. 14431445.

[7] S. Williamson, "Low cost microstrip filters and mixers at 43 GHz," in IEE Colloquium on MM-Wave Circuits and Technology for Commercial Applications, 1999, vol. 1999, pp. 3-3.

[8] K. Gong, W. Hong, Y. Zhang, P. Chen, and C. J. You, "Substrate Integrated Waveguide Quasi-Elliptic Filters With Controllable Electric and Magnetic Mixed Coupling," IEEE Trans. Microw. Theory Tech., vol. 60, no. 10, pp. 30713078, Oct. 2012.

[9] A. Hardock, R. Rimolo-Donadio, H.-D. Bruns, and C. Schuster, "Application of Vias as Functional Elements in Microwave Coupling Structures," IEEE Trans. Microw. Theory Tech., vol. 61, no. 10, pp. 3541-3550, Oct. 2013.

[10] G. A. Kouzaev, M. J. Deen, N. K. Nikolova, and A. H. Rahal, "Cavity models of planar components grounded by 
via-holes and their experimental verification," IEEE Trans. Microw. Theory Tech., vol. 54, no. 3, pp. 1033-1042, Mar. 2006.

[11] M. Sánchez-Renedo and R. Gómez-García, "Small-size planar tunable combline filter using decoupling walls," Electron. Lett., vol. 43, no. 9, p. 532, 2007.

[12] J. D. Martinez, S. Sirci, M. Taroncher, and V. E. Boria, "Compact CPW-Fed Combline Filter in Substrate Integrated Waveguide Technology," IEEE Microw. Wirel. Components Lett., vol. 22, no. 1, pp. 7-9, Jan. 2012.

[13] C. K. C. Tzuang and W.-T. Lo, "Printed-circuit realization of a tapped combline bandpass filter," in $\{$ IEEE $\}\{M T T\}-\{S\}$ \{International\} \{Microwave\} \{Symposium\} \{Digest\}, 1990, pp. 131-134.

[14] R. Levy, H.-W. Yao, and K. A. Zaki, “Transitional combline/evanescent-mode microwave filters," IEEE Trans. Microw. Theory Tech., vol. 45, no. 12, pp. 2094-2099, Dec. 1997.

[15] T. Stander and S. Sinha, "Ultra-compact capacitively loaded evanescent half-mode SIW filters for LTE applications," Int. J. Microw. Wirel. Technol., vol. 6, no. 05, pp. 487-490, Oct. 2014.

[16] R. J. Cameron, R. R. Mansour, and C. M. Kudsia, Microwave Filters for Communication Systems : Fundamentals, Design and Applications. Wiley, 2007.

[17] Zhibing Liang, Kuandong Gao, Yongmao Huang, Lianfu Liu, and Zhen Hai Shao, "A Ka band broadband bandpass substrate integrated waveguide filter," in 2012 th International High Speed Intelligent Communication Forum, 2012, no. 1, pp. 1-3.

[18] Y.-M. Yan, Y.-T. Chang, H. Wang, R.-B. Wu, and C. H. Chen, "Highly Selective Microstrip Bandpass Filters in KaBand," in 32nd European Microwave Conference, 2002, 2002, pp. 1-4.

[19] H. Zhong, R. Xu, and M. Zhan, "Design for $\{\mathrm{Ka}\}$-band wideband bandpass filter with three-line microstrip structures," 2008, pp. 351-353.

[20] Y. Tao, W. Hong, and H. Tang, "Design of A Ka-Band Bandpass Filter Based on High Order Mode SIW Resonator," in 2006 7th International Symposium on Antennas, Propagation \& EM Theory, 2006, pp. 1-3.

[21] Q. Zhang, Y. Dong, and J. Cao, "Dual-mode bandpass filter using microstrip SIR at Ka band," in 2009 Asia Pacific Microwave Conference, 2009, pp. 1401-1404.

[22] H. Shaman, S. Almorqi, O. Haraz, S. Alshebeili, and A. Sebak, "Millimeter-wave microstrip diplexer using elliptical open-loop ring resonators for next generation $5 \mathrm{G}$ wireless applications," in Proceedings of 2014 Mediterranean Microwave Symposium (MMS2014), 2014, pp. 1-4.

[23] D. Deslandes and K. Wu, "Millimeter-wave substrate integrated waveguide filters," in CCECE 2003 - Canadian Conference on Electrical and Computer Engineering. Toward a Caring and Humane Technology (Cat. No.03CH37436), vol. 3, pp. 1917-1920.

[24] X.-P. Chen and K. Wu, "Self-Packaged Millimeter-Wave Substrate Integrated Waveguide Filter With Asymmetric Frequency Response," IEEE Trans. Components, Packag. Manuf. Technol., vol. 2, no. 5, pp. 775-782, May 2012. 